\title{
Learning Schoolscapes in a Minority Setting
}

\author{
Enikő BIRÓ \\ Babeş-Bolyai University (Cluj, Romania) \\ Department of Modern Languages \\ eniko.biro@econ.ubbcluj.ro
}

\begin{abstract}
In my paper, I present a qualitative approach to the linguistic landscape of Hungarian schools in Sepsiszentgyörgy/Sfântu Gheorghe, Romania. These landscapes are called schoolscapes as they represent the material environment where texts and images "constitute, reproduce and transform language ideologies" (Brown 2012: 282). These manifestations reveal a lot about language learning and teaching in a formal educational environment. Beyond the simple representations of languages in education, we may trace more or less hidden curriculum details of foreign- and secondlanguage teaching (English/German, Romanian) in a Hungarian-Romanian dominant bilingual setting. My aim is to describe the visual manifestations of the differences and similarities between the languages taught to minority children and the mutual efforts of teachers and students to meet the basic challenges of learning and teaching these languages.
\end{abstract}

Keywords: linguistic landscape, bilinguals, hidden curriculum, language learning

\section{Linguistic landscape, language ideology}

Visual language can be as strong as the written word. The study of the signs has a long history; however, the term linguistic landscape was first used by Landry and Bourhis (1997: 25). The field of research called by this term has become a fast-developing subfield of applied linguistics, known as the study of public multilingual signs. It also forms part of sociolinguistics and language politics because linguistic landscape "is the visual representation of the individual and collective understanding of the experienced language policy and traditions of language use" (Tódor 2014: 530). Investigating the linguistic landscape is useful in regions where communities/ethnic groups with different linguistic-cultural backgrounds live together. Linguistic landscape focuses on signs, cultural symbols, and notices found in public spaces, so linguistic landscape becomes "a web of significances where languages are used in different ways, conveying 
different meanings and with different aims in mind" (Gorter-Cenoz 2014: 167). Inscriptions, signs, etc. have two basic functions: they either provide information (hence their communicative/informative function) or convey symbolic meanings; so, the symbolic function is always present. The symbolic function gains importance in a minority linguistic background. For example, it carries further symbolic reference in public spaces with bilingual informative signs. If the order of the languages used is controlled, it is also of importance which language appears first, etc. Therefore, the discussion of linguistic landscapes is inseparable from language ideologies. The linguistic landscape (LL) literature gives thorough analyses of the relationship between top-down and bottom-up signs: "between LL elements used and exhibited by institutional agencies which in one way or another act under the control of local or central policies, and those utilized by individual, associative or corporative actors who enjoy autonomy of action within legal limits" (Ben-Rafael et al. 2006: 10). The dominant and subordinate positions of language choices vary between top-down and bottom-up authors, and the dominant position is "expected to reflect a general commitment to the dominant culture, while the latter is designed much more freely according to individual strategies" (Gorter 2006: 10). Language ideology within the discussion of linguistic landscapes refers to a set of shared attitudes and beliefs of the given community about language or languages. It is "the cultural system of ideas about social and linguistic relationships, together with their loading of moral and political interests" (Irvine 1989: 255). Like any ideology, language ideology is shaped in a cultural setting. It is not merely an individual's perception of language use or attitudes towards their users but it is also related to collective perceptions and cultural hegemonies (Gal 1998). Moreover, language ideology is neither stable nor static and is closely linked to the notion of identity, helping to identify ourselves and to let others identify us. It is important that the impact of language policies can be analysed with the help of language practices and elements of linguistic landscape. As Shohamy (2006: 110) notes, the public space can be an arena for ideological battles: “... the presence (or absence) of language displays in the public space communicates a message, intentional or not, conscious or not, that affects, manipulates or imposes de facto language policy and practice". Linguistic landscape becomes a manifestation of language ideology and practice (Shohamy 2006), which help people to position them when they reflect upon their views on language learning, on bilingualism or multilingualism. 


\section{School spaces and questions raised by the present research}

The aim of this paper is to present a qualitative approach to the linguistic landscape of Hungarian schools in Romania. These landscapes are called schoolscapes as they represent the material environment where texts and images "constitute, reproduce and transform language ideologies" (Brown 2012: 282). These manifestations reveal a lot about language learning and teaching in a formal, educational environment. The linguistic ecosystem of schools provides a rich insight into the specific dimensions of school life. Schoolscapes represent excellent ways to explore the visual forms of the hidden curriculum regarding language ideologies in education (Johnson 1980, Shohamy 2006, Brown 2012, Aronin \& ÓLaoire 2012) through the examples of different languages. School spaces can be used to legitimize certain language ideologies. Hidden curriculum also refers to all those values and expectations which are not included in the written curriculum and at the same time reflect the more or less conscious educational philosophy of institutions (Brown 2012). According to Szabó (2015), "schoolscapes are determined not only by laws and local regulations, but by the visual practices of the given institution as well. Inscriptions and cultural symbols placed on the façade and the walls of the school building are tools for orienting the choice between various cultural and linguistic ideologies" (Szabó 2015: 24). Studies of the signage in schools can lead to a better understanding of what goes on inside schools and, as such, contribute to education research. Both in minority- and in majority-language medium schools, it is important to study the relationships between the mother tongue, the official language, and foreign languages. In a minority setting, the triple presence of the mother tongue-state language-foreign language offers many research topics (Bartha-Laihonen-Szabó 2013).

In Romania, the mother tongue of the majority, Romanian, is not taught as a foreign language to minority students, while English or German are clearly foreign languages. In my paper, I will try to present how schoolscapes evolve according to this situation and how the languages (Romanian, English, German, etc.) are represented in the schoolscape of Hungarian-medium schools in Romania. I will also describe the identified differences between teaching Romanian and teaching foreign languages represented in the schoolscapes. Moreover, schoolscape can be approached as a demonstration or materialization of the 'hidden curriculum' regarding language ideologies in education (Brown 2012). Further on, I will reflect on who the signs have been made or initiated by (school authorities, teachers, students, etc.). I will have a look at the various products themselves and discuss where and how long these signs and images are displayed. All these elements of schoolscapes are intertwined; they change continuously and mirror the local, national, and cultural ideologies of those participating in the schoolscapes. 


\section{The Hungarian ethnic minority and languages at schools in Szeklerland}

The largest Hungarian minority in the Carpathian Basin lives in Romania. The language of the Romanian majority has a dominant official status. Hungarians constitute the largest ethnic minority in Romania $(1,227,623-6.5 \%$ of the total population). ${ }^{1}$ Hungarian is not only the mother tongue but the language of everyday communication for dominant bilinguals ${ }^{2}$ in Szeklerland, ${ }^{3}$ who are also members of a national and cultural minority in Romania. Although there is a positive attitude towards multilingualism, which is regarded as a means of integration into the European community and global society, different attitudes and ideologies apply to the state language than to the Hungarian language, which indicates that people's attitudes towards the Romanian language are influenced by their views of state language policy. State language policy is quite often connected to the power and the dominance of Romanians as the majority group and stands for a top-down language policy.

Compulsory school age is 6. Children can choose from three kinds of school types in this region of Romania. Hungarian-medium schools offer teaching in the mother tongue (Hungarian) of the students, complemented with the state language programme. Mixed-medium schools mean that students can choose the language of instruction, either Romanian - with all subjects taught in Romanian - or Hungarian, again with all subjects taught in Hungarian, except the state language classes. Classes are not mixed; there are separate Romanian and Hungarian classes in each age-group. The third type is the Romanian-medium school, where the language of instruction, administration, etc. is Romanian. There are quite a few students of Hungarian ethnicity who join the Romanianmedium schools or Romanian classes of mixed-medium schools either because they come from mixed families or they hope for better opportunities in life by learning proper Romanian. Hungarians usually attend Romanian-medium schools and use Romanian on a daily basis outside the home in regions where they constitute the minority of the population. However, in those areas where they are in majority, Hungarian-medium education is widely available (the region called Szeklerland consists of three counties: Covasna, Harghita, and Mureş). Lacking the opportunity to practise Romanian in everyday life in Szeklerland, Hungarians rely on school education to learn Romanian. It is widely held that this is the main

1 Census 2011: https://en.wikipedia.org/wiki/Demographic_history_of_Romania\#20_October_2011_census.

2 Dominant bilinguals are bilinguals who are more proficient in one language as compared to the other language.

3 It is a historic and ethnographic area in Romania, inhabited mainly by Hungarians and Romanians, a region of three counties with slightly more than 800,000 inhabitants in Transylvania in Romania. 
reason why students are not able to acquire Romanian, the official language of the country, at an appropriate level. Romanian is a compulsory subject throughout the entire education system and some subjects, such as Romanian history, have to be taught through the medium of Romanian even in schools where Hungarian is the language of teaching. The main cause of the unsatisfactory outcome of Romanian instruction lies in teaching methods, which Kiss terms 'worstpractice' (Kiss 2011: 257). Romanian is taught as a first language, not as a foreign one, with a heavy emphasis on literary analysis. Consequently, "comprehension is limited and students only succeed by memorizing” (Kiss 2011: 256). On the other hand, English being the first foreign language they learn at school, many language learners report a good or even high level of English proficiency. The teaching of a foreign language starts in the second grade. At pre-school level, some kindergartens organize courses in a foreign language for which parents must pay. From the fifth grade on, a second foreign language is added.

\section{Research materials and methods of analysis}

In the course of work on the present study, 4 state schools were visited between February and April 2016, 2 Hungarian-medium schools and 2 mixed schools (Székely Mikó High School, Mikes Kelemen High School, Váradi József Primary School, and Berde Áron High School). There were 8 interviews made with primary school teachers and language teachers, and photos were also taken.

Table 1. The sources in the corpus

\begin{tabular}{clcc}
\hline Nr. & School type & Number of photos & Length of interviews \\
\hline 1 & Primary school & 62 & $45^{\prime}$ \\
\hline 2 & Primary school & 18 & $30^{\prime}$ \\
\hline 3 & Primary school & 22 & $40^{\prime}$ \\
\hline 4 & Primary school & 23 & $21^{\prime}$ \\
\hline 5 & High School & 21 & $46^{\prime}$ \\
\hline 6 & High School & 60 & $38^{\prime}$ \\
\hline 7 & High School & 84 & 1 h $^{\prime}$ \\
\hline 8 & High School & 50 & $43^{\prime}$ \\
\hline Total & & 340 & $346^{\prime}$ \\
\hline
\end{tabular}

The research method was a qualitative one and the 'tourist guide technique' was applied (Szabó 2015). This approach relies on a new fieldwork method that Szabó has developed. It is based on such forms of mobile data collection as the 'walking tour methodology' (Garvin 2010), as the researcher and the interviewee co-explore the space to be investigated. Szabó says about his method that, using it, 
the researcher acts as a tourist guided by teachers, for example, of the given school and explores the school's space while taking photos. The appointed guides and the teachers comment on the choice of language, symbols, and displays on the walls during their school tour and answer the researcher's ('the tourist's') questions about further details. By applying this technique, I was able to collect a lot of information easily on the signage and language choices and received background explanations concerning the teaching materials used, as my chosen guides were language teachers, except for the teachers in one of the primary schools where data were also collected. During the interviews with the teachers, I managed to draw the participants' attention to the hidden curriculum as well as to the implicit policies and ideologies revealed by the signs on display. It was also possible to briefly interview students from different classes and collect additional data from them. The insights recorded during this walking interview were analysed later and the photos were categorized and simultaneously investigated together with the audio recordings and their transcripts in accordance with other details of the research. This joint exploration was capable of combining the researcher's view, the teachers' opinions and the students' perspectives. The research focused on the process of how the schoolscape illuminated the hidden curricula of the state language and the foreign language(s) taught at the given school. In what follows, I will make use of a marketing concept in order to illustrate all the participants in this process. Therefore, I propose to analyse the schoolscape along the four Ps of the schoolscape mix. ${ }^{4}$ The analysis will cover (1) the agents and participants and present their interpretation of signs and displays (people); (2) the types of schoolscape elements displayed (product); (3) the places where these signs are displayed, because the location where they are exposed to public view carries informative, normative, and controlling references (place), and, finally, (4) the length of time for which the signs are displayed, i.e. whether the objects are intended for a permanent, long-term, or temporary demonstration (period).

\subsection{People}

With the help of the tourist guide technique, it was possible to elicit explanations about how certain signs, symbols, and exhibits were used. However, this method had its own limitations because interpretations of schoolscape items may have varied from participant to participant within the particular schoolscape. The question of agency came up as a complex factor and participants of schoolscapes could give different interpretations of a particular sign. For example, the stars in the photo below (Figure 1) were placed above the blackboard in a classroom of $10^{\text {th }}$

4 The term 'marketing mix' was first used by Neil Borden in 1953 as a business tool in marketing to determine a product's or brand's offer and is often associated with the following four Ps: price, product, promotion, and place. 
graders. At first sight, since they were painted in the Hungarian national colours, it appeared obvious that they were used as decorations for the $15^{\text {th }}$ of March, the Hungarian national holiday. However, their true meaning was revealed by the sign makers, i.e. by the students themselves, who said that the signs had been designed for the Christmas holiday. Nevertheless, painting Christmas stars in the Hungarian national colours created a particular relationship between explicit universal signs and implicit language ideologies.

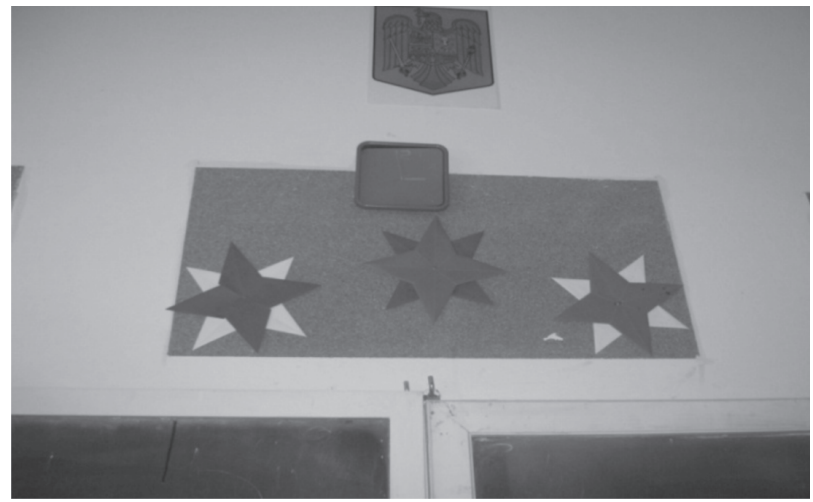

Figure 1. Christmas decoration comes in red-white-green

One of the participants of the schoolscapes is the school authority itself. It is this body that is to determine under what conditions and where signs can be placed in each classroom, etc., which conveys different language ideologies and metadiscourses on Romanian and foreign languages. As Romanian is the language of administration and it must be ubiquitous, the official notices and leaflets are in Romanian. In Hungarian-medium schools, the non-official documents are usually monolingual notices as the readers of these signs are mostly Hungarians.

Teachers/educators represent the next group of participants in the process; they are the main sign makers. They enjoy relative freedom either to strictly follow the national curriculum or to deviate from it. Within a minority setting and in metadiscourses, a different attitude is shown as opposed to top-down policy. Top-down policy requires teaching Romanian as a second language, and later as a mother tongue, so minority students should meet the same requirements as their Romanian peers. Teachers of the Romanian language may use methods and techniques, even materials which are normally required in the foreign-language teaching process. Hence, in some cases, teaching Romanian becomes more communicative - a method most frequently applied to promote the acquisition of foreign languages. Furthermore, it is the teachers' duty to display tableaux exhibiting linguistic norms, teaching aids and students' works (sometimes without any correction). Elements associated with teaching English are more 
prominent in high schools than in elementary school classes. In elementary schools, teaching Romanian is the main concern of teachers of Hungarian students. It is this setting in which their first contact with the Romanian language takes place and the foundations of their familiarity with it are laid down.

Students, the third group of agents within a schoolscape, are the main sign readers. Their language choice and language use, however, are characterized by two globalized and specialized linguistic registers, and depict a spontaneous rather than conscious attitude (Figure 2). There is a gradually increasing indifference over time: elementary schoolscapes are more vivid while the $11^{\text {th }}$ and $12^{\text {th }}$ graders' classroom walls are almost bare.

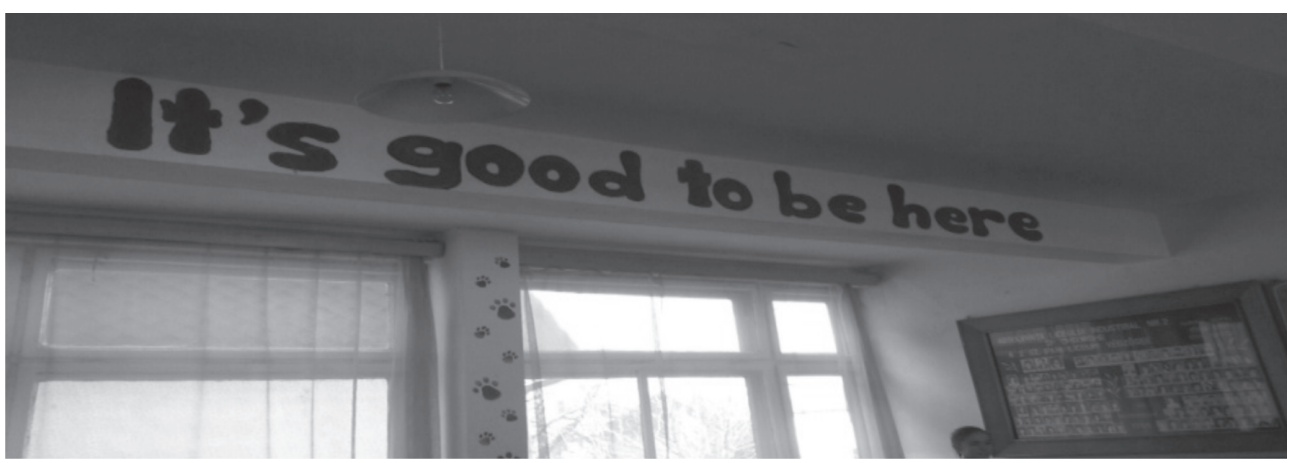

Figure 2. Becoming global

\subsection{Products}

The totality of the artifacts was categorized into several groups regardless of their Romanian- or English-language content. First of all, there are administrative texts, which are often highly normative and monolingual (Romanian). The structure of the school year, fire or evacuation plans on classroom doors, official notices of the Education Ministry on boards are compulsorily written in Romanian and they are printed and signed by an official. Bilingual signs are mainly notices as well, which on their turn could facilitate language learning in a minority setting (Figure 3). These notices are, however, controlled and usually carefully designed, reflecting a top-down policy of the school authority. In Hungarian-medium schools, there are fewer Romanian monolingual notices. All those that are locally produced are in Hungarian as the addressees are the members of a particular school.

The third major group of signage in the schoolscape included students' works displayed with the aim to encourage their learning; therefore, sometimes even teachers' corrections are missing. These displays are frequently changed and in many cases there are elements of a hidden curriculum, or 'off-the-curriculum' embodiments of creativity and teacher enthusiasm. Many examples of students' 
language use came up during project work, especially when its final results were exhibited. However, the lack of students' projects in schoolscapes might mean either the lack of a hidden curriculum or alignment with the official curriculum requirements.

The fourth large group of signs (tableaux with grammar rules, teaching aids, hand-outs, etc.) reflects normativity. They are present in schoolscapes in order to fit top-down language ideologies. Tableaux are gradually disappearing both in elementary and high schools. In elementary schools, only Romanian tableaux are displayed, those in foreign languages are missing. However, even in high schools grammar rules, verb derivation tableaux in Romanian outnumber foreign language ones. Except some English irregular verb lists, schoolscapes do not reflect any grammar-based foreign-language teaching methods, showing that linguistic performance is due to a rule-centred approach in education and language proficiency is dominated by metalinguistic discourse. The signs, maps, and symbols found in schools are not written but symbolic representations of language and language learning ideologies. They mostly present the use of British English as the 'real' variety of English in a very transparent way. The interviews carried out with language teachers revealed that, although Great Britain was iconic for English and British English is highly represented, in metadiscourses a more diverse ideology was reflected and teachers claimed that they were carefully introducing American or even other dialects of English to the students in order for them to gain an insight into a more varied English-language culture. Signs and other items reflecting Romanian culture and language ideology are mostly connected to normativity (due to the tableaux) as well as to some curriculum-based literary works or writers (photos, images of Romanian authors and personalities, excerpts from literary works, etc.). An interesting group of products displayed in schoolscapes consists of locally produced materials, which showed considerable creativity to fit the bilingual or even multilingual context. These leaflets, notices, and images appear on the notice boards of classrooms and usually represent the joint work of teachers and students. In many cases, we can witness a mix of Hungarian, Romanian, and English. These hybrid practices reflect and strengthen tolerance, while they also represent bottom-up language ideologies. They symbolically combine the informative, entertaining, and trendy characteristics of the most valued and most widely read elements of a schoolscape.

\subsection{Place}

The placement and number of images, signs, and symbols can also convey different meanings. In primary schools, one can usually find a lot more signs compared with secondary schools (at upper secondary level, there are almost no signs). This is mainly due to elementary school teachers' hard work and enthusiasm as well 
as to requirements of methodology, whereas there is a gradually increasing lack of interest on behalf of high-school graduate students. There can be a psychological and sociological explanation to this phenomenon: in the age of images, virtual reality, and social networks, students may become immune to the abundance of messages around them. However, in schools, the placements of signs still carry emphatic meanings. While in elementary classrooms every single spot is utilized, in high schools, it is the institution and its management that decides which spots can be assigned for such purposes. It lies within their competence to select the places for the displays, which can be reflective of language policy and educational ideology (corridors might be left empty or the opposite). Signs and symbols reflecting national identities are usually exhibited in these main places, as, for example, tableaux with grammar rules are sometimes displayed above or below the blackboards which are considered as central/focal spots of a classroom.

Hidden or semi-hidden places are less noticeable. These places also carry a metalinguistic aspect because the displays are there but not perfectly visible as top-down policy and local language ideologies clash in a furtive manner. In certain cases, formal or official exhibits appear in these hidden places, even behind other notice boards, at the end of corridors, or in the neighborhood of lots of other, more colourful signage. According to the interviewees, these are never conscious acts. In a high school, where French as a foreign language is also taught, the only display exhibiting French culture and language is a notice board at the darkest end of a corridor, while English signs, notices are everywhere on the walls of the same school. On the other hand, specially designed places are carefully chosen by the agents of schoolscapes in order to emphasize the content of the displays. Students' works are exhibited on notice boards, by which they make their voice heard. These are temporary displays and are frequently changed. According to the interviewees, teachers pursue a twofold aim: they want "to make them aware" of the signs and to let them express themselves at the same time.

\subsection{Period}

The lifespan of these displays is different, which carries further meanings apart from their variety, the degree of involvement of the sign makers, and the place they are exhibited in. Permanent signs, displays, and symbols reflect the dominant language policy, i.e. the language ideology of the institution. They are found at entrances, on the walls of corridors, or in central spots in classrooms. They are supposed to be controlled and normative. They convey top-down language ideologies (state flag, map, tableaux). On the other hand, long-term signs and displays are commonly found on notice boards in and outside of the classrooms (changed each semester or once a year at least). They are both informative and instructive (notices, official documents, tableaux of grammar rules, etc.) or are 
of general interest (school year schedule) and written in Romanian. Some of them can also be of local interest (timetables, programmes, etc.) and are usually printed in Hungarian. The third and probably most exciting type of exhibits are the temporary displays which convey students' views on a variety of topics. They are often changed and mostly found on the walls of classrooms; they are rarely present on the walls of corridors (the language used is mostly Hungarian, Romanian, or English, rarely German). However, there is a general decrease in the number of signs and displays over time: elementary classrooms are very colourful, while those of the $9^{\text {th }}-12^{\text {th }}$ graders tend to be grey and boring.

\section{Discussion and conclusions}

In this paper, I have focused on the illustration and examination of schoolscape element varieties and on their reflection of language ideologies. Although each school can be characterized by a distinct schoolscape, I looked for certain common aspects which would reveal the hidden curriculum through the different examples of teaching languages. I hold that it is critically important to identify the agents - the sign makers, sign readers, and all other significant participants - and any authority (local, regional, or national government) that sets the rules for signs. The top-down public language displays in the school clearly support the Romanian language, while bottom-up displays show the dominance of Hungarian in the signs. Top-down policy is presented by the authorities of the institutions; the signs displayed by them mirror normative standpoints. Teacher encouragement and student involvement, i.e. the bottom-up ideology is reflected by the signs and objects ranging from no displays at all to an overcrowded surface, which, however, gradually disappears over the years. Schoolscapes in Szeklerland outline a multilingual environment (Hungarian-Romanian-English), which has been building up lately. Apart from the informative content of the signs, the choice of language represents a symbolic value for some or all of the participants.

The limited display of traditional language-teaching preferences in certain schools and the attitude of the teachers loyally observing the curriculum usually go together, with little or almost no reference to the hidden curriculum in such cases. On the other hand, the high-level visibility of students' works in Romanian and in English outline a hidden curriculum creatively designed by the teachers and carried out together with their students. These teachers back up their choices with firm statements in which they mark themselves off from the national curriculum. One can find differences in how the languages (Romanian, English, German, etc.) are represented in the schoolscape of Hungarian-medium schools in Romania, but this diversity results from the main differences of the second-language and foreign-language teaching curricula. Romanian language teaching lacks almost all 
the elements of communicative foreign-language teaching and what is displayed in the classrooms mainly depends on the teacher. Whenever the materialization of the 'hidden curriculum' takes place, it reflects the choice of the teachers and not of the official curriculum or language policies. Bottom-up ideologies are reflected in these instances of the schoolscape. Regarding foreign language teaching, the omnipresence of English is one of the most conspicuous markers of the process of globalization and shows the competitive advantage of the English language in this field. Still, classroom displays reflect teachers' effort and students' willingness to participate in this joint work. Students' works and locally produced materials can be further analysed in terms of the hidden curriculum in more detail. The place and period factors in this intertwined and continuously changing setting of a schoolscape is also worth studying. Although teaching Romanian as a foreign language to minority students is not aligned with language ideologies, it is visualized in the hidden curriculum, and so it appears in practice. The four Ps (people, product, place, and period) reveal a lot about language learning and teaching ideologies. There is a mix of conscious and unconscious choice of places, where the conscious choice embodies normativity and there is an emphasized control. The most interesting and varied elements are in constant change. Yet, official notices (permanent displays) are mostly overlooked.

Finally, further research is required to study the elements of the schoolscape in order to explore the material use of languages and language learning processes in schools and to come to a deeper understanding of ideologies shaped by these processes.

\section{References}

Aronin, Larissa-ÓLaoire, Muiris. 2012. The material culture of multilingualism. In: H. Marten, D. Gorter, L. van Mensel (eds), Minority languages in the linguistic landscape, 299-318. New York: Palgrave.

Bartha, Csilla-Laihonen, Petteri-Szabó, Tamás Péter. 2013. Nyelvi tájkép kisebbségben és többségben egy új kutatási területről [Minority and majority linguistic landscape: a new field of research]. Pro Minoritate 3: 13-28.

Ben-Rafael, Elieyer-Shohamy, Elena-Amara, Hassan Muhamad-Trumper-Hecht, Nira. 2006. Linguistic landscape as symbolic construction of the public space: the case of Israel. International Journal of Multilingualism 3: 7-30.

Brown, Kara. 2012. The linguistic landscape of educational spaces. In: Marten, Gorter, L. van Mansel (eds), Minority languages in the linguistic landscape, 281-298. Basingstoke: Palgrave Macmillan. 
Gal, Susan. 1998. Multiplicity and contestation among linguistic ideologies. In: K. Woolard, B. Schieffelin (eds), Language ideologies: practice and theory. Oxford University Press.

Garvin, Todd Rebecca. 2010. Responses to the linguistic landscape in Memphis, Tennessee: an urban space in transition. In: E. Shohamy, E. Ben-Rafael, M. Barni (eds), Linguistic landscape in the city, 235-251. Bristol: Multilingual Matters.

Gorter, Durk. 2006. Introduction: the study of the linguistic landscape as a new approach to multilingualism. International Journal of Multilingualism 3(1): $1-6$.

Gorter, Durk-Cenoz, Jason. 2014. Linguistic landscapes inside multilingual schools. In: B. Spolsky, M. Tannenbaum, O. Inbar (eds), Challenges for language education and policy: making space for people, 151-169. New York: Routledge.

Irvine, Judith, 1989. When talk isn't cheap: language and political economy. American Ethnologist 16(2): 248-267.

Johnson, Norris Brock. 1980. The material culture of public school classroom: the symbolic integration of local schools and national culture. Anthropology $\&$ Education Quarterly 11 (3): 173-190.

Kiss, Zsuzsa. 2011. Language policy and language ideologies in Szekler Land (Rumania): a promotion of bilingualism? Multilingua: Journal of CrossCultural and Interlanguage Communication 30(2): 221-264. doi:10.1515/ mult.2011.010.

Landry, Rodrigue-Bourhis, Richard. 1997. Linguistic landscape and ethnolinguistic vitality an empirical study. Journal of Language and Social Psychology 16(1): 23-49. doi:10.1177/0261927X970161002.

Shohamy, Elena. 2006. Language policy: hidden agendas and new approaches. London: Routledge.

Szabó, T. Péter. 2015. The management of diversity in schoolscapes: an analysis of Hungarian practices. Apples: Journal of Applied Language Studies 9(1): 2351. http://apples.jyu.fi/.

Tódor, Erika. 2014. The hidden curriculum of schoolscapes: overview of the bilingual school context. Journal of Romanian Literary Studies 8: 529-538. 